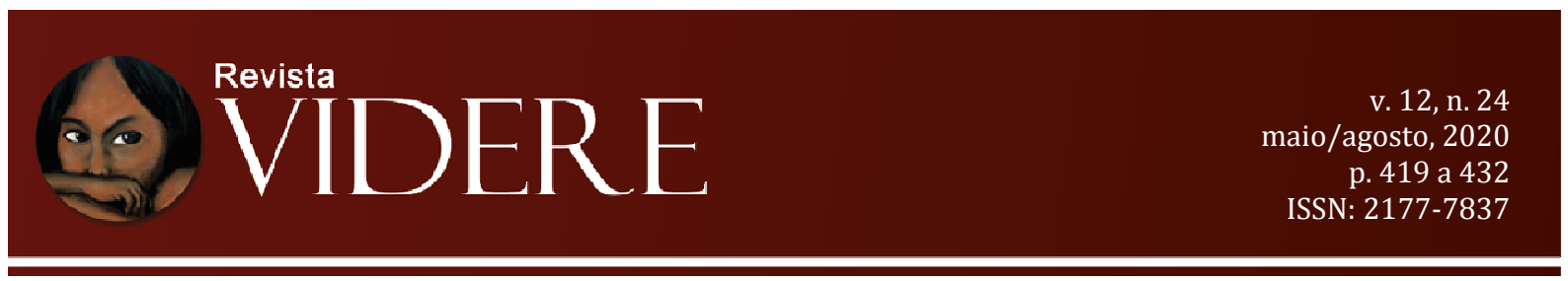

\title{
O MOVIMENTO DO DIREITO LIVRE E A POSSIBILIDADE DO JULGAMENTO CONTRA LEGEM
}

\author{
EL MOVIMIENTO DEL DERECHO LIBRE Y LA POSIBILIDAD \\ DE JUICIO CONTRA LEGEM
}

\author{
Raquel Passos Maia \\ Doutoranda em Teoria do Direito e Mestra em \\ Direito Constitucional (ULisboa) - Universidade de \\ Lisboa, Portugal. Faculdade de Direito da \\ Universidade de Lisboa. \\ E-mail: raquelpmaia13@gmail.com \\ OrcID: https://orcid.org/0000-0002-8630-9599
}

\author{
Aline Passos Maia. \\ Doutora em Direito do Trabalho (USAL) - \\ Universidad de Salamanca, Espanha. \\ E-mail: \\ OrcID:
}

\begin{abstract}
RESUMO: O Movimento do Direito Livre, iniciado ao final do século XIX, foi uma reação às correntes positivistas legalistas levadas ao exagero. Desta feita, esse movimento denunciava a existência de um direito independente da origem estatal, chamado de Direito Livre, bem como a falibilidade da lei como fonte única de direito. Um de seus mais famosos adeptos foi Hermnann Kantorowicz que, dentre outras ideias, defendia a possibilidade de julgamentos contra legem, a saber, defendia que em determinadas situações os magistrados podiam se distanciar do disposto na lei escrita. Assim, partindo de um caso ocorrido no ordenamento brasileiro, onde o Supremo Tribunal Federal decidiu pela não aplicação das regras dispostas na Constituição Federal acerca do veto presidencial, e tomando como base os estudos de Kantorowicz e a doutrina do Direito Livre, pretende-se aqui analisar qual a possibilidade e a fundamentação de decisões judiciais se distanciarem de leis claras e unívocas tendo como fundamento a escolha critérios interpretativos de cariz consequencialista.
\end{abstract}

PALAVRAS-CHAVE: Movimento do Direito Livre; interpretação judicial; decisão contra legem.

RESUMEM: El Movimiento del Derecho Libre, que comenzó a fines del siglo XIX, fue una reacción a las corrientes legalistas positivistas conducidas a la exageración. Esta vez, este movimiento denunció la existencia de un derecho independiente del origen del Estado, el llamado Derecho Libre, así como la falibilidad de la ley como única fuente de derecho. Uno de sus seguidores más famosos fue Hermnann Kantorowicz, quien, entre otras ideas, abogó por la posibilidad de juicios contra legem, es decir, que en ciertas situaciones los magistrados podrían distanciarse de las disposiciones de la ley escrita. Por lo tanto, a partir de un caso ocurrido en en el ordenamiento brasileño, donde la Corte Suprema Federal decidió no aplicar las reglas establecidas en la Constitución Federal acerca del veto presidencial, y en base a los estudios de Kantorowicz y la doctrina del Derecho Libre, se pretende aquí investigar la 
posibilidad y la base de las decisiones judiciales lejas de leyes claras y unívocas, que adoptan criterios interpretativos de naturaleza consecuencialista.

PALABRAS-CLAVE: Movimiento del Derecho Libre; interpretación judicial; decisión contra legem.

\section{Introdução}

Pretende a presente pesquisa analisar a possibilidade de julgamentos contra legem. Neste intuito, bastante relevo é dado aos estudos feitos por Hermann Kantorowicz acerca do Movimento do Direito Livre e da possibilidade, ainda que em sede de exceção, de decisões judiciais se oporem frontalmente a legalidade estabelecida ${ }^{173}$.

Impende destacar, desde logo, que a percepção de que julgamentos contra legem podem ocorrer foi abordada nos estudos feitos por Kantorowicz não como forma de legitimar a desvinculação do juiz à lei. Distanciando-se bastante desse viés, os escritos de Kantorowicz voltaram-se muito mais a questionar os fundamentos do formalismo legalista levado ao exagero que imperou no século XIX, bem como denunciar situações que já aconteciam na realidade e experiência jurídica da época. Observou este autor que a estrita legalidade não garantia a correção e muito menos anulavam o subjetivismo nas decisões judiciais. Como bem aponta Manuel Segura Ortega (2019), a aceitação de forma positiva de decisões contra legem se dá em razão da razoabilidade e da correção que demonstram ter.

Tomando com base os estudos de Kantorowicz acerca do que ele chamou de Direito Livre se pretende aqui analisar a possibilidade da não aplicação judicial do disposto em normas claras e unívocas. Desta feita, o objetivo da presente pesquisa é analisar qual a possibilidade de juízes, no desempenho de suas funções, se afastarem de leis inequívocas na resolução do caso concreto. Tal afastamento da solução dada pela lei no caso concreto é possibilitado por métodos interpretativos ou é fruto da opção do intérprete judicial em atingir resultados já previamente escolhidos? Fazendo um contraponto com os estudos de Kantorowicz, decisões contra legem são fruto da razão ou da vontade?

Para o desenvolvimento do estudo proposto, o trabalho será dividido em três partes: primeiramente far-se-á síntese de um exemplo ocorrido no ordenamento brasileiro, onde o Supremo Tribunal Federal decidiu pela não aplicação da inequívoca disciplina constitucional acerca do veto presidencial. Em seguida, abordar-se-á as linhas do Movimento do Direito

\footnotetext{
173 Não no sentido de se opor a lei como fonte de direito ou ao sistema legalista, mas a possibilidade de decisões judiciais solucionarem determinados casos em sentido oposto ao prescrito legalmente.
} 
Livre, com ênfase em um de seus principais expoentes, Hermann Kantorowicz, no intuito de compreender melhor os objetivos reais desse movimento, bem como suas ideias acerca da vinculação do juiz à lei e da possibilidade de se darem julgamentos contra legem. Na terceira parte pretende-se entender a possibilidade de fundamentar e justificar decisões que se afastam de regramentos claros e unívocos.

Ao final do estudo serão tecidas as últimas considerações acerca do exposto e se responderá o problema formulado, a saber, qual a possibilidade e a fundamentação de decisões contra legem, levando em conta, neste intuito, as observações feitas por Kantorowicz.

A presente pesquisa possui um propósito descritivo e explicativo com abordagem qualitativa. Ressalta-se que foi utilizada a citação no corpo do texto como forma referenciação direta ou indireta do conteúdo de outros autores, e a citação em nota como forma explicativa de algumas considerações pertinentes. Todas citações possuem exata correspondência entre si e as respectivas referências bibliográficas dispostas ao final. Da mesma forma, se destaca que em determinados pontos do presente artigo, recorreu-se a doutrina de vários autores que se filiam a ideias e correntes divergentes. Todavia, tal atitude metodológica não se dá com o fito de enquadrá-los ou unificá-los em suas ideias. Apenas se recorre aos autores na medida em que suas ideias se ligam a algum ponto do texto. Por fim, destaca-se que foi utilizada a pesquisa bibliográfica como fonte prioritária, tendo como fonte de informação livros, artigos e legislação.

\section{Um exemplo atual de um problema antigo: o veto presidencial a "Nova Lei dos Royalties" e a postura do Congresso Nacional}

A decisão de tomar como ponto de partida um caso particular para, a partir de então, ascender a reflexão de problemas jurídicos fundamentais não é nova. Como ensina Arthur Kaufmann (2015), ainda que se parta de uma especificidade empírica, o verdadeiro objeto do conhecimento nunca se restringe a esta singularidade. $\mathrm{O}$ caráter distintivo da Filosofia enquanto Ciência se verifica na totalidade de seu objeto formal, na sua preocupação pelo o que é essencial, pelo todo e pelo contexto.

Desta feita, ainda que partindo de uma singularidade, o objetivo aqui não se limita a este caso concreto que se analisará neste intróito. Pretende-se aqui refletir sobre questões essenciais à Ciência do Direito, como a plenitude ou (in)completude do Ordenamento 
jurídico, a vinculação do juiz à lei, a legitimidade democrática e fundamentação de decisões contra legem. Dito isto, vejamos.

A Lei brasileira número 12.734 de 2012 (Projeto de Lei $n^{\circ}$ 2.565/2011) alterou as disposições legais que até então disciplinavam a partilha dos royalties devidos em função da exploração do petróleo, gás natural e demais hidrocarbonetos fluidos entre os Estados, Distrito Federal, Municípios e órgãos da administração direta da União. A nova disposição, a saber, o então Projeto de Lei $\mathrm{n}^{\circ} 2.565 / 2011$, foi alvo de veto parcial pela também então Presidente da República Dilma Rousseff. Seguindo as regras constitucionais que disciplinam o processo legislativo brasileiro, o veto presidencial retorna ao Congresso Nacional para apreciação, tendo este último órgão o prazo de trinta dias contados a partir de seu recebimento para análise do referido veto. Findando este prazo sem a apreciação do veto, este será colocado na ordem do dia da sessão imediata, sobrestando as demais proposições até sua votação final. Tudo isto conforme os incisos 4o e seguintes do artigo 66 da Constituição da República Federativa do Brasil, 1988:

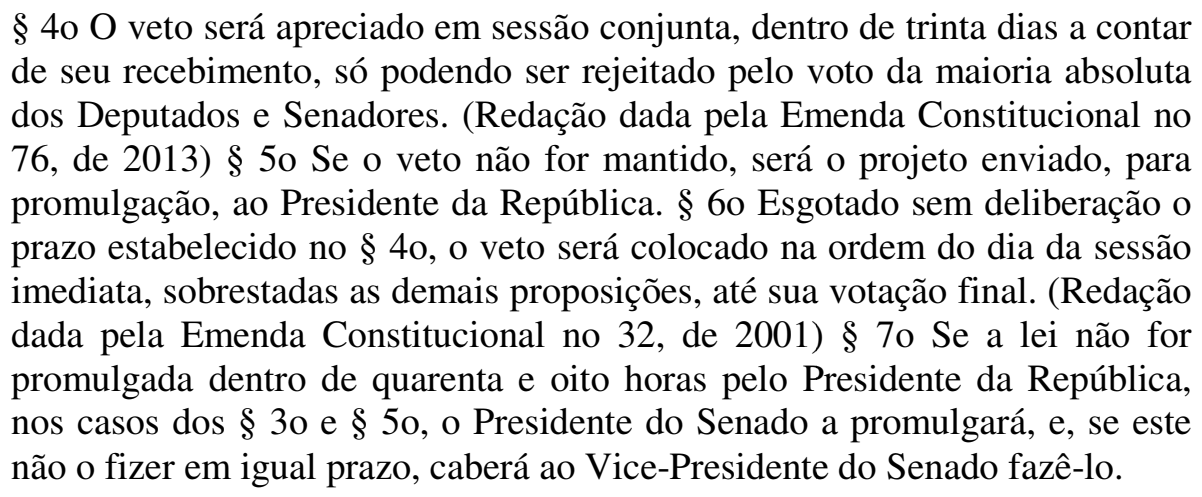

Como se vê, é evidente a consequência imposta ao Congresso Nacional pelo constituinte em caso de não apreciação dos vetos presidenciais no prazo estabelecido. Procedendo assim, perderá o Congresso Nacional parte de sua liberdade legislativa, a saber, será tolhida sua usual autonomia na definição de sua agenda política, lhe sendo proibido decidir acerca de outras matérias senão o veto presidencial. Tão grave consequência foi a forma que o constituinte achou para tentar inibir a inércia na apreciação dos vetos pelo legislador.

Entretanto, na prática brasileira, o Congresso Nacional ignorava o disposto na Constituição acerca dos vetos pendentes e, como consequência, no ano de 2012, já havia mais de três mil vetos presidenciais com análises dependentes de apreciação, vetos emitidos há mais de treze anos. Diante de tal situação, foi impetrado Mandado de Segurança n ${ }^{\circ} 31.816$ / 
Distrito Federal com pedido de liminar no Supremo Tribunal Federal (STF) questionando a apreciação do veto a "nova lei dos royalties" antes de todos os demais ainda por apreciar.

Em suma, o parlamentar impetrante contestou a apreciação de vetos ainda sem prazo vencido antes daqueles em que o prazo já se encontravam expirados. Como explanou o Ministro Gilmar Mendes (2016), o impetrante alegou também que a apreciação dos vetos deveria seguir critérios objetivos e razoáveis e não apenas critérios de conveniência política.

A decisão em aplicar a regra constitucional mesmo diante do cenário instalado - a saber, mesmo diante de mais de três mil vetos não apreciados e com prazos expirados —, até chegou a ser acolhida liminarmente pelo Ministro Luiz Fux, entretanto, foi posteriormente revista pelo Plenário do STF. Como bem salientou o então Ministro Teori Zavascki, uma decisão nesse sentido dificilmente seria confirmada, "especialmente pela gravidade das consequências que derivariam do puro e simples reconhecimento, com efeitos ex tunc, da inconstitucionalidade da prática até agora adotada pelo Congresso Nacional" ${ }^{174}$.

Muito embora as regras constitucionais acerca do veto presidencial e de sua superação fossem de clareza indiscutível, os antigos vetos ainda pendentes versavam sobre as mais variadas matérias, tais como a renegociação de débitos tributários e previdenciários, perdão de dívidas, Código Florestal, dentre outras. Nesse sentido, o STF levou em consideração em sua decisão final os graves impactos que a pura e simples aplicação da norma constitucional poderia desencadear nas seguranças jurídica, econômica e fiscal diante da situação fática desde há muito instalada. Como bem destacou o Ministro Luiz Fux em seu voto, a disciplina constitucional acerca do veto presidencial e de sua superação são de clareza meridiana e a situação fática instalada revelava total descaso em relação ao disposto pela Constituição:

Apesar da clareza meridiana da sistemática constitucional, o Congresso brasileiro vem ignorando, por completo, tanto o prazo peremptório de trinta dias para apreciação do veto pendente quanto a consequência imediata do seu descumprimento (i.e., o trancamento automático da pauta legislativa até a respectiva votação). $\mathrm{Na}$ prática, os parágrafos do artigo 66 da Constituição são frontalmente descumpridos sem qualquer pudor. Em consequência, acumula-se hoje no Congresso Nacional um estoque de 3.060 vetos pendentes de apreciação, todos com prazo constitucional já vencido. (grifo nosso).

Assim, decidiu o STF por maioria pelo indeferimento da liminar que autorizava o cumprimento do disposto constitucionalmente, a saber, o trancamento da pauta do Congresso Nacional até a apreciação em ordem cronológica dos vetos pendentes fruto da prática

174 Trecho da ementa do acórdão de relatoria do Ministro Teori Zavaski. Disponível em: http:// redir.stf.jus.br/paginadorpub/paginador.jsp?docTP=TP\&docID=3779575 
inconstitucional sedimentada pelo Congresso brasileiro, tendo em vista as consequências nas seguranças jurídica, econômica e fiscal do país.

Como apontado pela Ministra Cármem Lúcia, vários ministros que votaram a favor do indeferimento da liminar reconheceram em seus votos a inconstitucionalidade da prática adotada pelo Congresso Nacional ${ }^{175}$ :

(...) embora, repita, ninguém negue que houve descumprimento da norma constitucional, do art. 66, parágrafos 40 e 60 , e que a situação vem numa delonga muito acentuada e muito grave, mas entendo que o quadro exige decisão que não crie mais problemas, como foi demonstrado no voto divergente do Ministro Teori, do que teríamos com a prevalência da liminar. (grifo nosso).

Entretanto, mesmo assim, a maioria dos Ministros optaram pela não aplicação das regras constitucionais tendo em vista a situação já instalada.

\section{O movimento do direito livre versus a possibilidade de um direito livre}

Rudolf Stammler ao analisar as bases do movimento do Direito Livre apontou como possíveis sinais desse movimento as sentenças do magistrado francês Magnaud, — conhecido como "o bom juiz" — que através da aplicação de princípios de humanidade e solidariedade nos casos sob sua jurisdição, muitas vezes se afastava abertamente do prescrito nas leis positivas $^{176}$.

O Movimento do Direito Livre, tido por alguns como "livre da lei" (KAUFMANN, 2015, p. 175), caracterizou-se mais por denunciar uma situação já existente do que por estimular uma conduta subversiva dos juízes em relação a lei.

Da mesma maneira que as sentenças do "bom juiz" francês não tinham como objetivo violar a obediência que os juízes devem ao direito positivo, assim também os objetivos do Movimento do Direito Livre não se voltavam à libertação das amarras legais. Em algum casos, Magnaud decidia sem recorrer ou até mesmo em sentido contrário a disposições legais expressas. O Movimento do Direito Livre denunciava a existência de um Direito Livre, livre da origem estatal e que tinha sim aplicação nos litígios judiciais, muito embora isso não fosse admitido pelos intérpretes.

\footnotetext{
175 Trecho do voto da Ministra Cármen Lúcia. Disponível em: http://redir.stf.jus.br/ paginadorpub/paginador.jsp?docTP=TP\&docID=3779575

${ }^{176}$ Vale ressaltar que, como mencionado por Luis Recasens Siches na obra Panorama del Pensamiento Juridico en el siglo XX, (1963), não se deve as sentenças do juiz francês a origem do movimento alemão. Somente a postura do juiz Magnaud, bem como seu modo de decidir é tido por Stammler como relevante antecedente ao nascimento do Movimento do Direito livre.
} 
Para Hermann Kantorowicz, expoente nome do movimento, isso era claramente demonstrado na questão da colmatação das lacunas. Categoricamente este autor afirmou a existência de lacunas tanto no direito oficial, estatal, como no que ele chamava de direito livre, bem como criticou a "mania de grandeza" atribuída a Ciência Jurídica. "Solo la jurisprudencia se atreve a causa de su supuesta plenitud hermética a poder resolver cualquier problema real o imaginable y exige esta capacidad inclusive del último de sus novatos." (KANTOROWICZ, 2019, p. 44).

No que diz respeito ao problema das lacunas, estas seriam preenchidas pelo Direito Livre mesmo que isso não fosse admitido pelos tribunais ${ }^{177}$. Assim, quando os tribunais preenchiam as lacunas - com o Direito Livre, segundo Kantorowicz - afirmavam que se havia decidido com um direito estatal até então desconhecido, como ele mesmo explica:

Unicamente el Derecho livre, con la espontaneidad de sus decisiones y la plasticidad emotiva de su contenido frente al caso dado, puede colmar las lagunas y, de hecho, siempre las colmó. Esta situación no sufre alteración por hecho de que el mismo jurista que así procede y que indubitavelmente modifica la ley, estima tal actividad inadmisible y no la practica con plena conciencia. El último autor que ha escrito sobre las lagunas en la ley, Zitelmann, aprueba afortunadamente la descrita actividad del juez; pero declara haber de "mejorar" el término "modificación" puesto que dicha voz le produce "escrúpulos de conciencia". (KANTOROWICZ, 2019, p. 42).

Em suma, Kantorowicz observou notável diferença entre a Ciência do Direito e a prática dos tribunais. Afirmou a existência de um direito independente do Estado, mas que não se confundia com a noção de direito natural que até então se tinha e que ele chamou de Direito Livre. Como bem sintetizou Ramon Badenes Gasset:

(...) el sustrato del derecho estatal está constituido por el Derecho libre, que viene a ser en sustancia el antiguo Derecho natural, pero concebido no como universal e inmutable, sino como en continua transformación y adaptación a las exigencias del ambiente social. (BADENES GASSET, 1959, p. 191).

Deste modo, como observado Segura Ortega, Kantorowicz abre um leque bastante amplo de possibilidades para o que ele chama de Direito Livre. Diz Segura Ortega “(...) el concepto de Derecho livre no esta explicitado de un modo completo. Podría decirse que hay una cierta indeterminación y ambigüedad siendo muy probable que esté buscada con plena conciencia." (SEGURA ORTEGA, 2019, p. 12 ).

\footnotetext{
${ }^{177}$ Aqui Kantorowicz claramente critica a doutrina de Ernst Zitelmann, importante autor da época sobre o tema das lacunas. Segundo Zitelmann, as decisões judiciais fundamentadas pela via da analogia não criavam direito. A norma alcançada analogamente já era direito vigente, sendo lacunosa não a lei, mas o conhecimento dela até aquele momento.
} 
Diante de tal indeterminação conceitual, a identificação dos doutrinadores da época com o movimento variava de acordo com o conceito de Direito Livre que imperava. A falta de objetividade conceitual, ora assumindo tons mais brandos, ora se revestindo de um discurso mais radical, teve como consequência a recusa de alguns autores em se identificarem como adeptos do movimento.

Desta feita, diversos autores tiveram seus nomes associados ao Movimento do Direito Livre, seja apenas como precursores - representados por aqueles que, de algum modo, criticavam a infalibilidade da lei —, seja como participantes efetivos do movimento. Mesmo entre seus partidários assumidos, havia diferenças entre os chamados moderados e os chamados radicais. Isso porque, como já mencionado, dentro um conceito vagamente construído, vários tons de discursos podiam ser a este associado. (REICHEL, 1921).

Provavelmente, alguma concepção errónea dos escritos de Kantorowicz advenha desses fatores: primeiramente do movimento não ter conseguido construir conceitos teóricos bem definidos, bem como do fato de, dentro desse contexto, Kantorowicz ter encampado ideias impactantes - pelo menos para a época - e que mereciam uma prévia explicação teórica robusta e bem definida.

Uma das ideias consideradas impactantes defendidas por Kantorowicz, por exemplo, foi ele ter considerado que o juiz podia decidir contra o disposto na lei, isto é, dele ter admitido a possibilidade de decisões contra legem. Para este autor é dever do juiz se ater aos textos legais unívocos no desempenho de sua função jurisdicional. Nada obstante, o juiz não só poderá, bem como deverá se desprender do disposto na lei nos casos onde a solução dada pela lei não é clara, ou seja, quando na aplicação da lei não se consegue ter certeza da solução conferida, bem como nos casos onde o juiz esteja convencido de que a solução dada pela lei não parece ser a mesma solução que o Estado daria naquele momento específico da aplicação da norma ${ }^{178}$. Nesses casos, afirma o autor "En ambos los casos dictará el juez la sentencia que según su convicción el actual Poder del Estado habría decretado, si hubiese pensado en el caso de autos. Si el juez no fuese capaz de formase tamaña convicción, se inspirará en el Derecho libre.” (KANTOROWICZ, 2019, p. 65)

Uma afirmação nesse sentido, que admite decisões contra legem é impactante, de certo modo, até nos dias atuais. Daí ser possível imaginar a indignação dos juristas mais

\footnotetext{
${ }^{178}$ Ressalta-se que o autor também fala na possibilidade de decisão judicial arbitrária nos casos complicados e duvidosos em termos quantitativos, como por exemplo nas indenizações por danos morais, mas essa situação não é de grande relevo para a presente pesquisa.
} 
apegados a lógica dedutiva em relação aos escritos de Kantorowicz ${ }^{179}$. Conquanto, como visto, foi exposto por Kantorowicz as hipóteses em que o juiz estaria autorizado a decidir em sentido contrário à lei. Além do mais, Kantorowicz inicia seu discurso reafirmando a obrigatoriedade do magistrado em se ater aos textos legais unívocos no desempenho de sua função jurisdicional.

Contra as críticas que surgiram, a saber, contra os argumentos acerca do perigo de decisões arbitrárias e da ausência de segurança jurídica, Kantorowicz responde que, se não se pode confiar no juramento feito pelos magistrados, não se pode confiar em nada. Somando a isso, a multiplicidade de juízes e a possibilidade de recursos ou de revisão das decisões, seriam, igualmente, argumentos de combate contra tais críticas. Já em relação a falta de previsibilidade das decisões, afirma o autor que este não passa de um belo ideal: “¿Quién comenzaría un proceso, en que el, según se puede prever, perderá?" (KANTOROWICZ, 2019, p. 67).

Desta feita, os esforços de Kantorowicz se voltaram primeiramente a demonstrar a existência de um direito positivo mais além das leis emanadas pelo Estado, a denunciar a insuficiência e a não plenitude da lei como fonte de direito. A formulação de um novo conceito de direito - que inclui o Direito Livre — , de uma nova metodologia jurídica — que abandona a lógica dedutiva —, e de uma nova teoria do conhecimento jurídico — que admite o papel da vontade e mitiga o papel da razão no fenômeno jurídico — , são consequências dessa primeira constatação.

Nesse sentido, quando Kantorowicz fala de um Direito Livre, tal liberdade se refere a origem estatal. Para tanto, como mencionado, Kantorowicz se utiliza da constatação das lacunas e da sua colmatação para denunciar a insuficiência da lei estatal como fonte de direito em determinados casos. São nessas circunstâncias que o juiz estaria autorizado a recorrer diretamente ao Direito Livre, ou seja, nesses casos o juiz estaria "livre da lei", da lei insuficiente.

Entretanto, como se sabe, não só o Direito, mas sua interpretação e aplicação são sempre dependentes de vários aspectos, sejam sociais, históricos, culturais ou econômicos. Exemplificativamente, até mesmo a interpretação gramatical de um dispositivo legal — tido como o método mas simples e seguro - dependerá do significado que determinado signo possui em determinado contexto histórico. A ideia do Movimento do Direito Livre, a saber,

${ }^{179}$ É óbvio que declarações no sentido de defender a possibilidade de decisões contra legem despertam críticas sob vários vieses. Citou-se acima o descontentamento daqueles que acreditam na dedutividade lógica das decisões, no silogismo perfeito entre norma e decisão, mas há, também, questionamentos mais profundos, ligados à política, ao plano institucional e ao princípio da separação dos poderes, por exemplo. 
da existência de um direito além do proclamado pelas normas estatais advém, justamente, da ideia não liberdade e de dependência do Direito e do fenômeno jurídico a essas outras contingências.

\section{A justificação de decisões contra o disposto na lei e a sua relação com o direito livre}

De forma simplificada, julgamentos contra legem são aqueles que se mostram frontalmente em oposição ao disposto pelo texto da lei. Da interpretação literal do dispositivo legal extrai-se uma solução e esta não é o caminho adotado pelo intérprete judicial na decisão do caso em apreço.

Em geral, a justificação de decisões que claramente se opõem ao prescrito na lei se dão através da escolha de critérios interpretativos de cariz consequencialista. $\mathrm{O}$ intérprete se afasta do critério literal em virtude das consequências maléficas que aplicação do texto da lei ocasionaria. Segundo a doutrina de Neil McCormick, é quando a interpretação literal faz com que o texto seja frustrante com relação a seus próprios objetivos. Manuel Atienza explica que para McCormick, muito embora a interpretação linguística tenha prioridade no processo interpretativo - já que é por ela que se fixa o significado possível dos textos —, mesmo assim, este estágio interpretativo necessita ser complementado e, em alguns casos, ainda pode ser ultrapassado:

O argumento linguístico que fixa o significado possível dos textos é, em todo caso, essencial, mas pode ser ultrapassado e dar lugar assim a uma interpretação contra legem. Esse último tipo de interpretação pode ser admitido quando o texto contém uma contradição lógica, de forma tal que não haja nenhuma possível leitura capaz de afastá-la, mas também quando existe um absurdo axiológico, isto é, quando a interpretação linguística da lei faz com que o texto seja frustrante com relação a seus próprios objetivos, ou então irrealizável, ou seja, totalmente contra os princípios jurídicos ou da justiça em abstrato, ou do senso comum. (ATIENZA, 2002, p. 221 e 222).

Decisões contra à lei muito se assemelham ao conceito de interpretação ab-rogante adotado por Thibaut. Para ele a interpretação ab-rogante diz respeito não só a possibilidade de o intérprete corrigir a letra da lei, mas, também, de deixar de aplicá-la nos casos em que de sua aplicação resultaria numa decisão injusta. Segundo Ramon Badenes Gasset, para Thibaut, a injustiça da decisão é ocasionada pela ausência do sentido lógico que a lei supostamente deveria ter. (BADENES GASSET, 1959, p. 384).

A interpretação literal é um dos estágios da interpretação normativa. É o ponto de partida do intérprete que, fazendo uso de outros critérios, se empenha em concretizar a norma. Assim, o processo de aplicação da lei não se resume e nem para no critério literal. Desde os 
ensinamentos de Savigny que se sabe da existência dos critérios literal, histórico, sistemático, teleológico, todos de aplicação simultânea e não hierárquica. (LARENZ, 2005, p. 194).

Desta feita, o que especificamente vem a ser uma decisão contra legem? Uma decisão que soluciona a demanda no sentido oposto ao proposto pelo sentido literal tido por mais usual? Até que ponto uma decisão que muda o entendimento que se tinha de uma lei não se confunde com uma decisão contra legem?

Com bastante clareza Chaim Perelman explica que muitas vezes, com o fito de evitar a aplicação de determinada norma em determinado caso, pode o intérprete proceder à criação de uma lacuna contra legem. Nessas situações, existe norma regulamentando a situação, mas o intérprete considera que a norma não é aplicável àquela situação específica e decide por solucionar o caso ignorando a solução dada pela norma existente.

Finalmente os casos mais flagrantes são aqueles em que intérpretes, desejando evitar a aplicação da lei, em dada espécie, restringem-lhe o alcance introduzindo um princípio geral que a limita e criam assim uma lacuna contra legem, que vai de encontro às disposições expressas da lei." (PERELMAN, 2004, p. 67).

Isso se dá porque o estrito cumprimento da legalidade pode conduzir a efeitos distintos pelo pretendido pela própria lei. Neste sentido, há decisões que formalmente respeitam a lei, a saber, que aplicam a lei no seu sentido inequívoco e usual, no entanto acabam por produzir resultados incompatíveis com os desejados pela própria norma. Como diz Segura Ortega, concordando com Kantorowicz - a estrita legalidade não garante a correção da decisão, nem tampouco elimina os riscos de subjetivismo.

Sin embargo, es indudable que en determinadas ocasiones, por supuesto excepcionales, la estricta observancia de la legalidad puede produzir efectos diferentes a los previsto en la propia ley. En efecto, a veces nos encontramos con resoluciones que respetan formalmente la legalidad pero que en el fondo la vulneran abiertamente. (SEGURA ORTEGA, 2019, p. 25).

Por esta razão, Robert Alexy considera a pretensão de correção uma qualidade inerente tanto as normas jurídicas, como as decisões judiciais, seja de forma implícita ou explícita. Para Alexy, na medida em que se formula juízos práticos, que ordenam, proíbem ou permitem algo está, implicitamente, formulando-se pretensões de correção. E isso é inerente a norma, de forma que a ausência de tal pretensão retira da norma seu caráter jurídico. (ALEXY, 1994, p. 41).

Quando ausente a pretensão de correção, se forma uma contradição que parece nascer no seio da própria norma e não na sua incompatibilidade com outra no sistema (antinomia). É o que Alfonso García Figueroa (2014) chama de contradição performativa ou pragmática. 
Nessas situações, a impossibilidade de cumprimento da norma se dá por alguma razão de índole lógica, empírica ou pragmática.

No caso analisado no ponto de partida da presente pesquisa é inequívoco que a impossibilidade de aplicação das regras constitucionais se deu por mudanças nas circunstâncias reais vigentes, pela situação criada e sedimentada através da postura inconstitucional do Congresso brasileiro.

O pedido do parlamentar impetrante do Mandado de Segurança citado, no sentido da aplicação das regras constitucionais acerca da apreciação do veto, nem sequer tinha como real intenção o cumprimento das normas constitucionais. Como bem salientado no voto do Ministro Teori Zavascki, sob o pretexto de se fazer cumprir a Constituição se alcançaria a impossibilidade de apreciação de novos vetos. Certamente tal resultado não era o desejado pela norma constitucional.

Isso significaria, na prática, que, a pretexto de fazer cumprir, como se deve, o prazo do $\S 40$ do art. 66 da CF, uma decisão dessa natureza decretaria a impossibilidade material, pelo menos por longo espaço de tempo, da apreciação tempestiva de novos vetos presidenciais que venham a ser apresentados em futuro próximo. Paradoxalmente, portanto, nas circunstâncias de fato que agora se apresentam, o comando no sentido de determinar o estrito cumprimento da Constituição, inclusive quanto ao passado, operaria efeito contrário ao desejado pela norma constitucional.

Que a opção pela interpretação literal da lei dava mais força aos argumentos e ao resultado desejado pelo parlamentar impetrante não é só claro como, também, admissível. No entanto, o raciocínio do magistrado se difere do pensamento pragmático de um advogado comprometido na tentativa de atingir um resultado pré-estabelecido. Como nos lembra Carlos Cossio (COSSIO, 2018, p. 9) ao magistrado se exige uma atitude neutra, comprometida tão somente com a verdade jurídica. Pelo menos, prima facie.

Uma decisão no sentido do simples cumprimento do disposto pela Constituição como foi a liminar deferida pelo Ministro Luiz Fux —, mesmo sendo fiel ao prescrito pelo Texto Maior, configura um exemplo fiel do que Segura Ortega chamou de resoluções contra legem que formalmente respeitam a lei, ou ao que McCormick chamou de interpretações contra legem, ou ao que Thibaut chamou de interpretação ab-rogante. O ponto de união entre esses conceitos é a relação frustada entre o sentido literal da norma e o seu próprio objetivo diante de determinadas circunstâncias.

De volta ao exemplo dado ao início, no que diz respeito a interpretação das regras constitucionais não havia dúvidas acerca do seu significado, tampouco eram regras 
contraditórias. O problema era de cunho teleológico-valorativo, já que o significado legal claro e inequívoco provocaria problemas se aplicado literalmente diante de situação instalada.

Disso se observa que a partir do momento que o intérprete judicial constata que a aplicação da letra da lei deságua em consequências inaceitáveis, ele procurará de alguma maneira evitar tal aplicação. Como explana Perelman, a partir daí inicia-se um processo de busca ou elaboração de teorias que permitam se afastar de determinado texto legal.

A solução mais simples consiste em opor o espírito à letra da lei; indo mais
longe, opor-se-á à vontade do legislador real a vontade do legislador
razoável, que não pode querer o que é socialmente inaceitável. Elaborar-se-
ão teorias que permitirão limitar o campo de aplicação de certos textos
(teorias do abuso do direito, da ordem pública internacional, por exemplo)
ou alargá-lo (interpretar a expressão «violação da lei» como «violação de
uma regra de direito», o que permite ao supremo tribunal a anulação de uma
sentença que viola uma lei estrangeira ou um princípio geral do direito).
(PERELMAN, 2002, p. 506).

Por constatar casos como o aqui analisado contemporâneos à sua época é que Kantorowicz identificou o destacado papel da vontade em detrimento da razão tanto nas decisões judiciais, como na Ciência do Direito. Destacou que a vontade em atingir um resultado já previamente fixado - o que compreende a vontade de se esquivar de um resultado não querido - é o que rege o intérprete na escolha dos textos legais e das regras de interpretação, tudo sob a capa de um suposto rigor lógico dedutivo.

Daí que os escritos de Kantorowicz são tidos como realistas, na medida em que ele escreve sobre o que de fato se passava na realidade jurídica da época, empenhado em demonstrar o papel que a vontade e os elementos emocionais já desempenhavam nas decisões judiciais, muito embora não fossem admitidos.

La interpretación extensiva o analógica en un caso, y la textual o restritiva en el otro, no se inspira en la ley y en la lógica, sino en el Derecho libre y en la voluntad, sea en la voluntad de conseguir el resultado deseado, sea en la de esquivar el indeseable. (KANTOROWICZ, 2019, p. 50).

E mais adiante acrescenta:

En efecto, algunas veces la jurisprudencia erigía construcciones tan forzadas que su incompatibilidad con el texto legal se hizo patente a la persona más miope; otras vezes se agarraba a la ley y producía resultados en contradicción hiriente con las "necesidades de la vida" (o sea, por regla general, con el Derecho libre de comerciantes, mujeres, obreros). (KANTOROWICZ, 2019, p. 52).

Quando Kantorowicz ventila a possibilidade de decisões contra legem, ele se refere a decisões que vão de encontro ao literalmente estabelecido na lei, ou seja, a decisões 
formalmente contra legem, e que, nem por isso, implicava em decisões injustas ou inadequadas.

Fazendo um contraponto com a teoria de McCormick, é por esta razão que este autor considera que mesmo que a decisão não seja fruto de um processo dedutivo das normas gerais do sistema, ainda assim ela será considerada racionalmente justificada desde que demonstre ter coerência e congruência com o Direito, bem como possua consequências aceitáveis. É o que ele chama de fazer sentido no sistema (ter coerência e congruência) e fazer sentido no mundo (produzir consequências aceitáveis).

Vale explicitar que Neil McCormick é um neo-institucionalista que considera a doutrina do raciocínio jurídico complementar à Teoria do Direito. Segundo Carla Faralli, para este autor:

(...) o estudo do raciocínio jurídico tem por objeto o conjunto das práticas argumentativas compartilhadas pelos juízes. Esse conjunto é centrado na forma e na estrutura da argumentação, mais do que em seus conteúdos: pode ser definido, portanto, como uma teoria procedimental do raciocínio jurídico." (FARALLI, 2006, p. 51 e 52).

Ele admite que há casos jurídicos onde a dedução não é suficiente no processo de justificação da decisão (hard cases). Nesses casos, o juiz deve recorrer a outros critérios de justificação - que ele nomeia de justificação de segundo grau —, que são a consistency, a coherence, e o consequentialist argument. Tudo isso para comprovar que mesmo em casos onde a dedução não é suficiente, ainda assim a argumentação não é fruto da arbitrariedade, mas de uma cadeia argumentativa racionalmente justificável.

Onde Kantorowicz vê o papel da vontade, McCormick o afasta desde que a decisão que não é fruto da dedução silogística - comprove possuir coerência, congruência e consequências desejáveis. Para McCormick mesmo nesses casos ainda sim se estaria no campo da racionalidade argumentativa justificável.

Tais situações são problemas teológicos-valorativos que se mostram no processo de aplicação da norma. É bem claro, por exemplo, nos casos onde a lei não prevê exceções, nos casos onde há modificações nas circunstâncias, no contexto de aplicação, bem como nas situações onde há uma variação nos valores da sociedade.

$\mathrm{O}$ alcance do elemento textual na interpretação é comumente levantado quando se tenta atribuir limites a atividade criativa do intérprete. Quando Karl Engisch aponta os casos de normas indeterminadas, onde o objetivo ou a vontade do legislador não são claramente reconhecidos e se faz necessário uma interpretação extensiva ou restritiva, estas só podem ocorrer na medida em que não contradigam com o sentido literal indiscutível já acessado 